University of Nebraska - Lincoln

DigitalCommons@University of Nebraska - Lincoln

2006

\title{
Atomic force microscopy of Bacillus spore surface morphology
}

Ruth A. Zolock

Air Force Institute of Technology

Guangming Li

Air Force Institute of Technology

Charles Bleckmann

Air Force Institute of Technology

Larry Burggraf

Air Force Institute of Technology

Douglas C. Fuller

Wright-Patterson AFB

Follow this and additional works at: https://digitalcommons.unl.edu/usafresearch

Part of the Aerospace Engineering Commons

Zolock, Ruth A.; Li, Guangming; Bleckmann, Charles; Burggraf, Larry; and Fuller, Douglas C., "Atomic force microscopy of Bacillus spore surface morphology" (2006). U.S. Air Force Research. 33.

https://digitalcommons.unl.edu/usafresearch/33

This Article is brought to you for free and open access by the U.S. Department of Defense at DigitalCommons@University of Nebraska - Lincoln. It has been accepted for inclusion in U.S. Air Force Research by an authorized administrator of DigitalCommons@University of Nebraska - Lincoln. 


\title{
Atomic force microscopy of Bacillus spore surface morphology
}

\author{
Ruth A. Zolock ${ }^{a}$, Guangming Li ${ }^{b}$, Charles Bleckmann ${ }^{\mathrm{a}, *}$, Larry Burggraf $^{\mathrm{b}}$, Douglas C. Fuller ${ }^{\mathrm{c}}$ \\ ${ }^{a}$ Department of Systems and Engineering Management, Air Force Institute of Technology, 2950 Hobson Way, Bldg 640, \\ Wright-Patterson AFB, OH 45433-7765, USA \\ ${ }^{\mathrm{b}}$ Department of Engineering Physics, Air Force Institute of Technology, 2950 Hobson Way, Bldg 640, Wright-Patterson AFB, OH 45433-7765, USA \\ ${ }^{c}$ Primary Care Services Flight, Wright-Patterson AFB, OH 45433-7021, USA
}

Received 8 May 2005; received in revised form 3 November 2005; accepted 4 November 2005

\begin{abstract}
Bacillus spore surface morphology was imaged with atomic force microscopy (AFM) to determine if characteristic surface features could be used to distinguish between four closely related species; Bacillus anthracis Sterne strain, Bacillus thuringiensis var. kurstaki, Bacillus cereus strain 569, and Bacillus globigii var. niger. AFM surface height images showed an irregular topography across the curved upper surface of the spores. Phase images showed a superficial grain structure with different levels of phase contrast and significant differences in average surface morphologies among the four species. Although spores of the same species showed similarities, there was significant variability within each species. Overall, AFM revealed that spore surface morphology is rich with information, which can be used to distinguish a sample of about 20 spores from a similar number of spores of closely related species. Statistical analysis of spore morphology from a combination of amplitude and phase images for a small sample allows differentiation between, B. anthracis and its close relatives.
\end{abstract}

(C) 2005 Elsevier Ltd. All rights reserved.

Keywords: Spore surface; AFM; Bacillus; B. anthracis

\section{Introduction}

It is difficult to rapidly identify and discriminate the pathogenic $B$. anthracis from its ubiquitous close relatives $B$. cereus and $B$. thuringiensis. Principally distinguished genetically by plasmids, it has been suggested that $B$. cereus, $B$. thuringiensis, and B. anthracis could be considered one species (Daffonchio et al., 2000; Helgason et al., 2000), or at least, are very closely related (Vilas-Boas et al., 2002). These organisms may even occupy overlapping ecological niches. A DNA sequence-based study has shown close matching between pathogenic strains of the three species (Ticknor et al., 2001).

B. cereus, a common soil microorganism is a causative agent of food poisoning and many human infections (Rosovitz et al., 1998). B. thuringiensis forms insecticidal parasporal protein crystals during sporulation and is produced commercially as an insecticide (Schnepf et al., 1998). B. anthracis, the causative agent of anthrax (Thorne, 1993), has recently been

\footnotetext{
* Corresponding author. Tel.: +1 937255 3636x4721; fax: +1 937656 4699.

E-mail address: charles.bleckmann@afit.edu (C. Bleckmann).
}

the object of much attention (Higgins et al., 2003). B. globigii is not closely related to these three species, and its taxonomic status has been disputed. However, it is now thought to be a subspecies of $B$. subtilis. Because this organism has been used as simulant for $B$. anthracis in microbial dispersion experiments, it was used to contrast the other three, more closely related organisms. Methods to rapidly distinguish small numbers of $B$. anthracis spores from spores of its less pathogenic cousins are currently of interest.

Invented in 1986, atomic force microscopy (AFM) has developed into a powerful tool for studying the natural surfaces of biological materials (Binnig et al., 1986; Radmacher et al., 1992), providing both topographic information and local mechanical and biochemical property characterization (Jandt, 2001). AFM produces images by raster scanning across the sample surface a sharp, pyramid-shaped tip at the end of a small, flexible cantilever. In tapping mode, oscillating the probe cantilever limits the tip-sample interaction and reduces contact time and lateral forces experienced by the sample during scanning (Hansma, 1999). Capturing amplitude changes of probe movement during a scan produces a topographic image. Phase images are generated by mapping the phase lag of the cantilever oscillation resulting from local tip-surface interaction, relative to the phase of the drive oscillation. 
Phase lag measures increasing time-delay of the AFM probe cantilever oscillation relative to the piezo-electric driver resulting from tip-sample interactions. The phase lag is produced by energy dissipation at the sample surface, which depends on material properties such as adhesion, stiffness, and viscoelasticity (Babcock and Prater, 1995; Bar et al., 2000).

Although the surface properties of living bacteria and fungal spores have been studied, AFM has only recently been applied to detailed morphological investigation of bacterial spores (Chada et al., 2003; Dufrene, 2000, 2002; Dufrene et al., 1999; Muller et al., 1996; Sokolov et al., 1996; Umeda et al., 1998; van der Mei et al., 2000).

Several protective layers surround a core of DNA and enzymes in Bacillus spores. For B. cereus, B. thuringiensis, and $B$. anthracis, the outermost integument is the exosporium. Transmission electron microscopy (TEM) revealed the exosporium to be a thin, layered structure (Gerhardt and Ribi, 1964; Liu et al., 2004). The exosporium influences spore hydrophobicity and organism pathogenicity (Charlton et al., 1999). Enzymes associated with the exosporium surface may limit premature germination (Todd et al., 2003). However, recent studies have shown the exosporium to be nearly featureless when imaged by AFM (Chada et al., 2003).

Several studies of spore surface properties suggest that the closely related species could be differentiated on the basis of their surface structures. First, the spores exhibit different degrees of hydrophobicity (Doyle et al., 1984; Koshikawa et al., 1989). B. cereus is the most hydrophobic, followed by B. thuringiensis, and B. anthracis (Doyle et al., 1984). High hydrophobicity implies a capability to strongly adhere to nonpolar substrates that are in contact with water (Ronner et al., 1990).

In spite of decades of work, there is little indication of the true surface morphology of the spores. Although spore sections and freeze-etch surface images have been examined extensively (Aronson and Fitz-James, 1976) only recently has work been done on spore surface morphology of unmodified or untreated spores (Chada et al., 2003). We report investigations of the surface morphology of B. cereus, B. thuringiensis, $B$. anthracis, and B. globigii spores using intermittent contact (tapping mode) AFM in a reduced humidity environment.

\section{Materials and methods}

\subsection{Microorganisms}

B. cereus strain 569 , B. thuringiensis var. kurstaki, B. anthracis Sterne strain (Thraxol-2, Code 235-23), and B. globigii var. niger spores were obtained from the Air Force Research Laboratories, Biomechanisms and Modeling Branch, Brooks Air Force Base, Texas. Bacterial cultures were grown from lyophilized spores, on Bacto ${ }^{\circledR}$ nutrient agar $(23 \mathrm{~g} / \mathrm{l}$; Difco), for 7 days at $37^{\circ} \mathrm{C}$. Spore cultures were washed with, and resuspended in, cold deionized sterile water. Suspensions were triple filtered using cellulose filter paper (Whatman ${ }^{\circledR} 1$ ) to remove cell debris, and centrifuged at $3000 \times g$ at $4{ }^{\circ} \mathrm{C}$ for $10 \mathrm{~min}$ after each filtration to concentrate spores. A Petroff
Hausser Counting Chamber was used to quantify spores in the final suspension $\left(\sim 10^{8}\right.$ spores $/ \mathrm{ml}$ for each culture).

\subsection{Sample preparation}

One sample of each species was prepared for examination with the AFM. Spores were mounted on freshly cleaved, Highly Ordered Pyrolytic Graphite (HOPG, ZYH Grade SPI-3, SPI Supplies ${ }^{\circledR}$ ) by spin-coating. A $100 \mu 1$ droplet of the spore suspension was placed on the middle of the graphite substrate and allowed to sit undisturbed for $5 \mathrm{~min}$. The sample was then spun at $2000 \mathrm{rpm}$ for $1 \mathrm{~min}$.

\subsection{Atomic force microscopy}

All imaging was done in tapping mode using a Nanoscope IIIa Scanning Probe Microscope (Digital Instruments, Santa Barbara, California, USA) with a 'J' scanner (AS-130, Digital Instruments). Silicon probes of resonant frequency 200 $400 \mathrm{kHz}$ were used (Model TESP, Digital Instruments). New cantilevers were used for each sample to prevent crosscontamination. Seven to ten spores of each species, selected randomly, were imaged by AFM (Zolock, 2002). Both height and phase images were captured. The scan rate was $0.5 \mathrm{~Hz}$. The drive frequency was adjusted lower than the resonant peak of the cantilever so that it coincided with an approximate 10 percent decrease in the vibration amplitude.

A humidity control chamber minimized the effects of naturally occurring water vapor on the sample surface. Nitrogen gas (from a liquid $\mathrm{N}_{2}$ tank), introduced at $<5 \mathrm{psi}$, purged the imaging system for several minutes. Gas flow was then reduced to maintain a low positive pressure in the chamber throughout the scanning period.

\subsection{Statistical analyses}

To further characterize and distinguish the spore surfaces, AFM phase data from several sub-samples of spore surface configurations were analyzed with descriptive statistics. A total of 74 spore-image subsamples were analyzed in detail: 26 for B. anthracis $(B a), 12$ for $B$. cereus $(B C)$, and 18 for B. globigii $(B g)$. The 18 phase images of $B$. thuringiensis were divided into two groups, protein crystals $(B t c)$ and spores $(B t)$. The distinctive $B t c$ images were readily distinguished from other images by the regularity in height and phase images for the protein crystals. Generally, the more complex, phase images were more useful to distinguish between spore surfaces than the relatively simple height information.

\section{Results}

The AFM images of the spore surface morphology were reproducible. The filtration step of sample preparation likely removed the relatively fragile exosporium leaving the surface of the endospore for imaging (Chada et al., 2003). There was no indication of damage to the spore surface by the imaging process in spite of repeated scans of the AFM tip over the same 
area over long time periods (up to five hours). Images appeared stable over scan sizes ranging from $2 \mu \mathrm{m}^{2}$ to $500 \mathrm{~nm}^{2}$. Spores were generally ellipsoidal, $1.5-2 \mu \mathrm{m}$ long and $750 \mathrm{~nm}-1 \mu \mathrm{m}$ wide. The B. cereus sample had the largest population of spores adhering to the smooth graphite surface, followed by the $B$. anthracis, B. globigii, and B. thuringiensis samples. The differences in adherence reflect expected differences in surface hydrophobicity, and thus spore-graphite adhesion.

Individual spores were easily resolved from the graphite substrate by their characteristic size and shape. Some irregular features, believed to be vegetative or incompletely sporulated cells were also observed. Typical spore images are shown in Fig. 1. Only the top surface of spores was imaged reliably. Images of the vertical edges of the spores were distorted by tipsample interaction.

Fig. 2 shows a $750 \mathrm{~nm}^{2}$ portion of the surface of a spore of each of the four species studied. The images on the left (A, C, E, G) are surface images (height data), presented without digital manipulation. The curvature shows the natural arc of the upper surface of the spore. In this imaging mode, spores of all four species showed similar topography-shallow grooves, steps, and bumps. Surface features were generally subtle, not extending more than $30 \mathrm{~nm}$ above or below the average surface. There was no obvious periodicity or order in the surface features.

Fig. 2, phase images (B, D, F, and H), for the same areas shown in the surface images described above, are the result of probe-spore surface interactions. A non-homogenous surface with a non-regular, grain-like appearance showed no regular pattern or periodicity.
Less than half of the $B$. thuringiensis spores appeared with parasporal crystals. The structures of these parasporal crystals, which exhibited 111 and 100 faces of a cubic lattice, were consistent with the structure of Cry 2 toxin (Schnepf et al., 1998). Fig. 3 shows a phase image of a B. thuringiensis parasporal crystal accounting for the regular shape of the upper surface.

Phase images (right-side images in Fig. 2) reflect the relative adhesion of the AFM probe tip and spore surface particles. Statistical analyses of the vertical phase data show consistent differences between spore surface properties of the various species (Fig. 4). Spore surface-grain diameter, aspect ratio, width of phase lag distribution, and mean phase-lag were characterized. Although there was no simple correlation between AFM phase contrast and a single material property, phase imaging mapped variations in sample properties at resolution of $\sim 10 \mathrm{~nm}$.

Fig. 4 provides visual summaries of the statistical summary of data from spore images, both from different spores and different parts of the same spore. Box and whisker plots provide a graphical summary of the analyses-horizontal lines show lower, median, and upper quartile values. Skewness is indicated if the median line is not centered in the box. Whiskers, lines extending above and below the box, show the extent of the rest of the data. Outliers, data with values beyond the ends of the whiskers, values more than 1.5 times the interquartile range away from the top or bottom of the box, are indicated by plus signs. The notches in the box are a graphic confidence interval about the median of a sample. A side-byside comparison of two notched box plots is the graphical
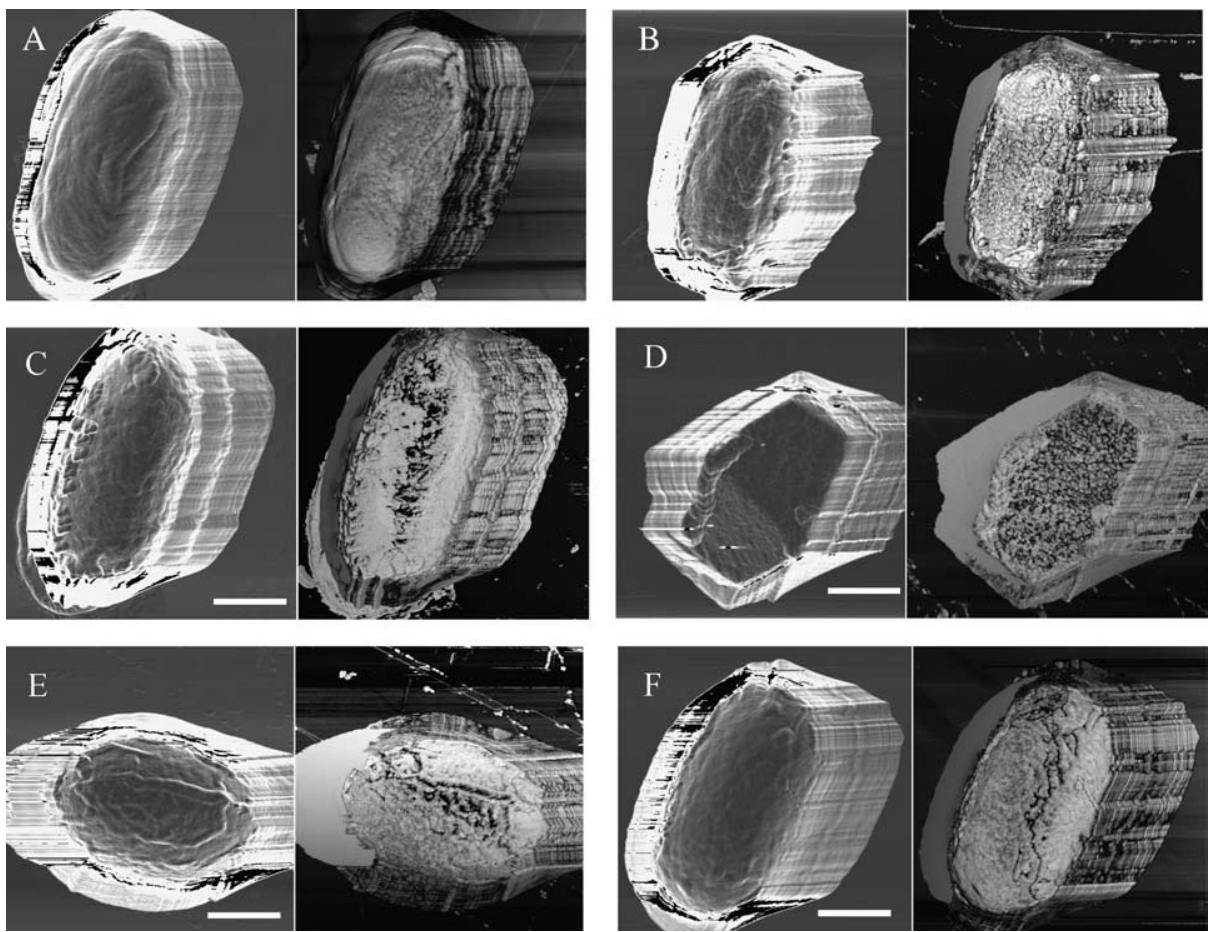

Fig. 1. AFM images of Bacillus spores. Left image, edge enhanced height data; right image, phase data. Scale bar=500 nm; A. B. cereus; B. B. globigii; C. B. thuringiensis; D. B. thuringiensis, parasporal crystal; E. B. anthracis with vein-like structures; F. B. anthracis without vein-like structures. 


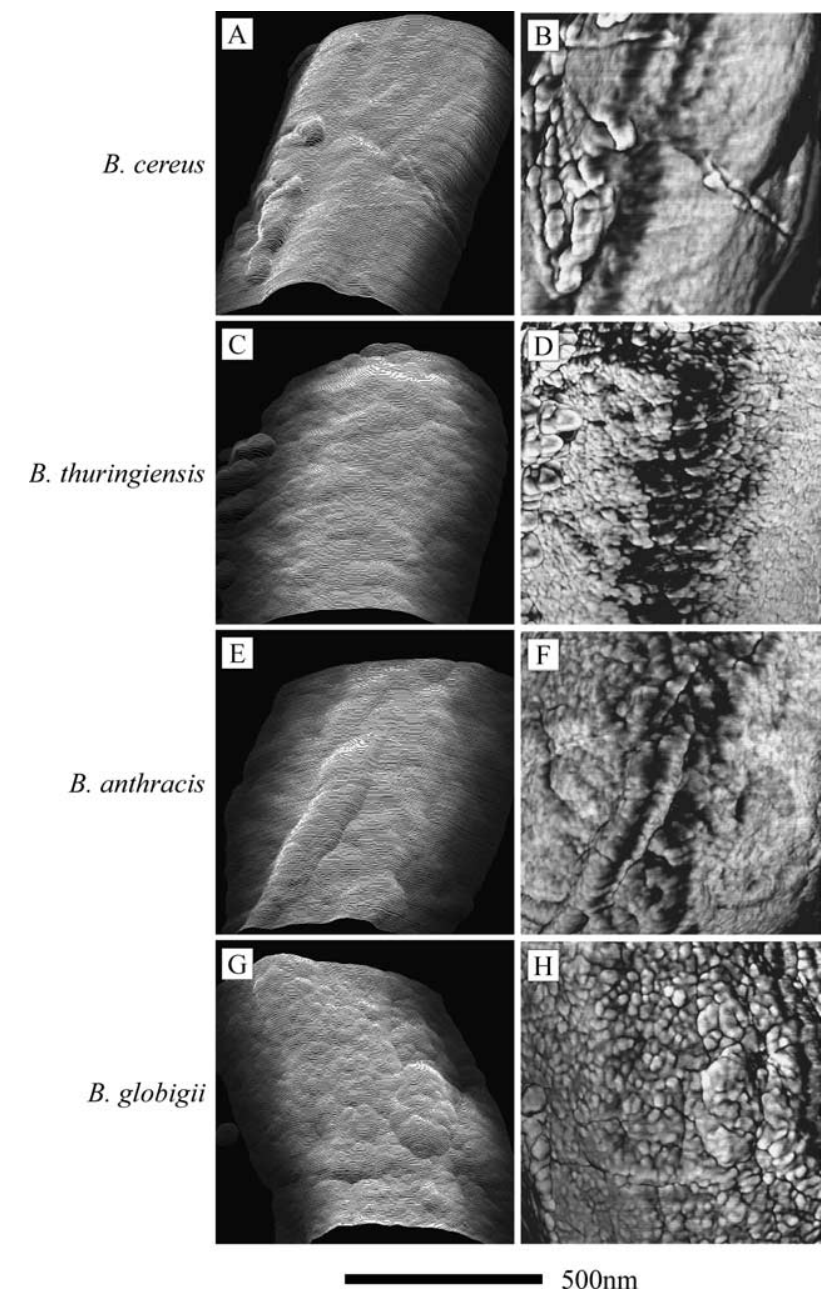

Fig. 2. Tapping mode height and phase images scanned at $750 \mathrm{~nm}^{2}$. The images on the left are line graphs of the height data with the $y$-axis pitched at $60^{\circ}$. The phase images are on the right. The vertical scale of the line images is from 0 to $100 \mathrm{~nm}$.

equivalent of a $t$-test. Surface features analyzed included surface grain diameter (Fig. 4A), the aspect ratio (length to width) (Fig. 4B), width of phase lag distribution (vertical to the surface) (Fig. 4C), and phase-lag center position (vertical to surface from the top reference zero) (Fig. 4D).

The Mean Surface Grain Diameters (Fig. 4A) increased from $B a(8.24 \mathrm{~nm}), B c(8.61 \mathrm{~nm}), B t(9.79), B g(12.29 \mathrm{~nm})$ and $B t c$ (12.91). $B a$ and $B c$ spore surface-grain diameters are very similar, with a narrower distribution for $B a$ than for $B c$. The median grain diameters of $B g$ and $B t c$ spore surfaces are significantly larger than for the other spores. (The probability value of the ANOVA for this group was 5.11 ${ }^{-6}$, suggesting that the probability of observing this diameter range by chance, given no difference in the means, is less than $\sim 5 / 1,000,000$.) Differences in $B g$ morphology, such as larger grain diameter for $B g$ compared to the more closely related organisms $B a, B c$, and $B t$, is not unexpected.

Aspect, or length-to-width, ratios for the surface grains (Fig. 4B) were very close for all of the organisms, 2.49 for $B a$, 2.70 for $B c, 2.45$ for $B g, 2.53$ for $B t$, and 2.23 for Btc. The Btc

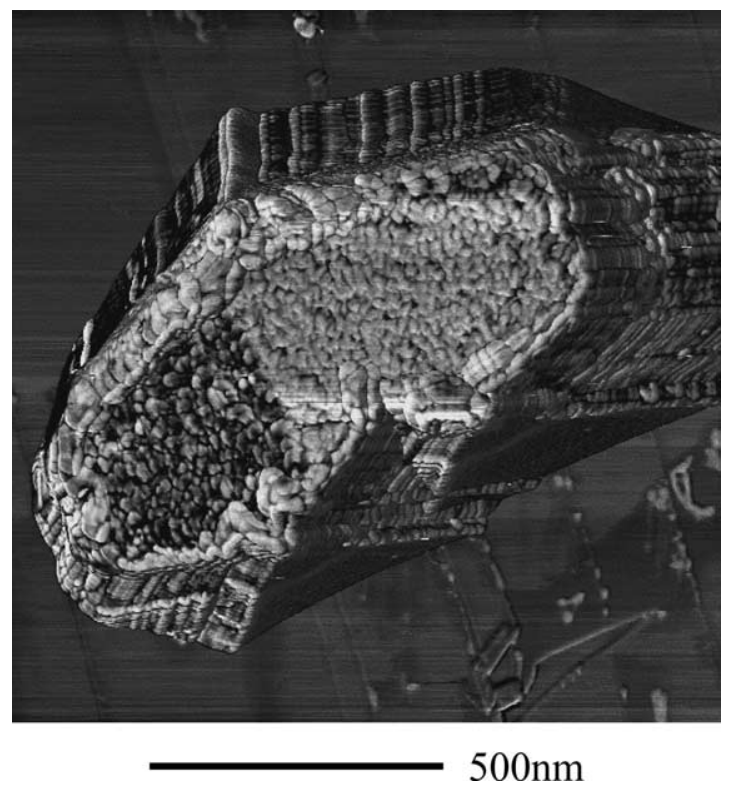

Fig. 3. Phase image of a $B$. thuringiensis parasporal crystal. The crystal faces intersect at an angle of $\sim 148^{\circ}$.

crystals exhibited flat surfaces and linear intersections, which are easily distinguished. The surface grains of Btc crystals were statistically different from those of the other spores (larger and more symmetrical). $B c$ spore surface structures showed the most asymmetrical and broadest particle aspect distribution. Difference in particle symmetry combined with the very different phase signature of $B c$, suggests that the materials in $B c$ spore surfaces are also qualitatively different from those $B a$ and $B t$.

The phase variance and mean for $B c$ were significantly smaller than all others (Fig. 4C). Bt had the largest phase lag variation over the surface, with a mean separation of 40 degrees between the 5\%- and the 95\%-histogram surface. A wide phase distribution indicates regions of high and low phase-lag, or strong and weak adhesion to the spore surface. $B a$ (28.33 deg) and $B c$ (12.89 deg) had relatively uniform, noninteractive surfaces. This suggests that the $B c$ surface consists mainly of a uniform, low-adherent material. The other spores had larger contributions of other phases, reflected by the distribution width. $B a$ spore images can be distinguished from $B c$ and Btc merely by the mean and width of the phase distributions. The asymmetry of the $B t$ and $B g$ phase distributions suggests another way to distinguish them from $B a$.

Fig. 4D shows the means of the phase-lag distributions. These means generally reflect the differences in distribution width, another indicator of phase-lag distribution over the spore surface. Distribution of phase means show that $B g$ and $B t$ materials are more heterogeneous than those of $B a$ and $B c$. Although the means of the phase distributions overlap, the ranges are much narrower for $B c$ and Btc than for the other spores, suggesting that a more homogenous phase dominates these spore surfaces (Fig. 4D) as is obviously the case for Btc. Comparison of the $B a$ phase distribution to the other 

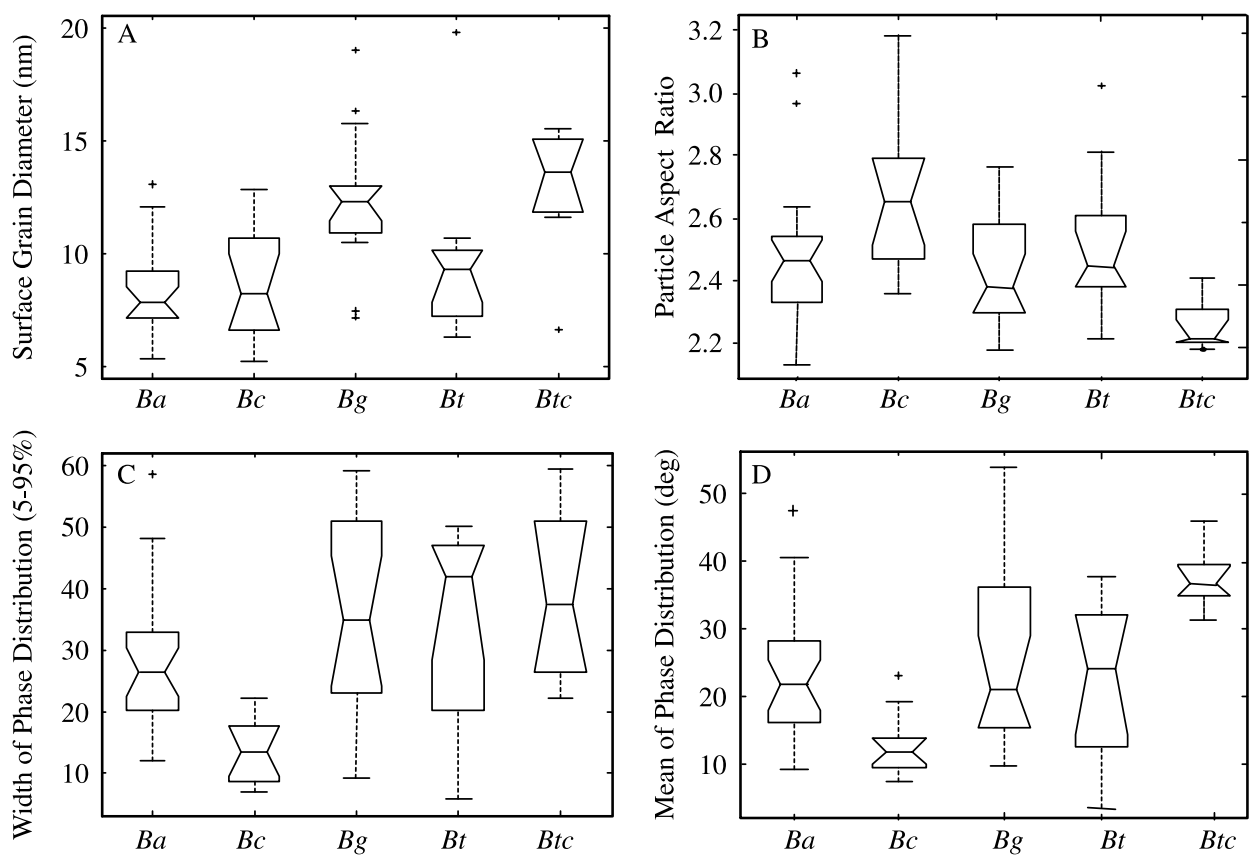

Fig. 4. Spore surface grain analyses ANOVA results. Box upper and lower lines represent samples 25th and 75th percentiles, midline is sample median, distance of midline from center indicates skewness. Whiskers show extent of data, + indicates outliers. Data from $26 \mathrm{Ba}$ images, $12 \mathrm{Bc}, 18 \mathrm{Bg}$, and $18 \mathrm{Bt}$ images. See text for descriptions statistical analyses.

distributions using the non-parametric Wilcoxon/KruskalWallis rank-sum test shows that $B c, B t$, and $B t c$ distributions are not centered at the same location as the $B a$ distribution.

We also compared variances of $B a$ phase distribution with $B t, B c$, and $B g$. The O'Brien variance test shows that the $B a$ distribution has variance significantly different from $B t$ and $B g$ (null probability of 0.0073 and 0.0199 , respectively), while variances of $B a$ and $B c$ were not significantly different (null probability of 0.9968 ). This analysis is consistent with expectation by inspecting Fig. 5, which shows average phase-lag distributions for spores, normalized to the $B a$ maximum. The shapes of the phase spectra contain qualitative information not captured by only the mean and width of these distributions. In addition to the differences in the mean and widths, these distributions have differently shaped wings. Some of the features in the differently shaped wings are significant distinguishing differences. An intensity of about 3 on Fig. 5 corresponds to a minimum of ten times variance in the phase spectrum noise at $95 \%$ confidence; larger features can be used to distinguish the spectra. As expected, the spectra for $B t$ and Btc spores for which the only difference is visible parasporal crystals, show qualitative similarities and

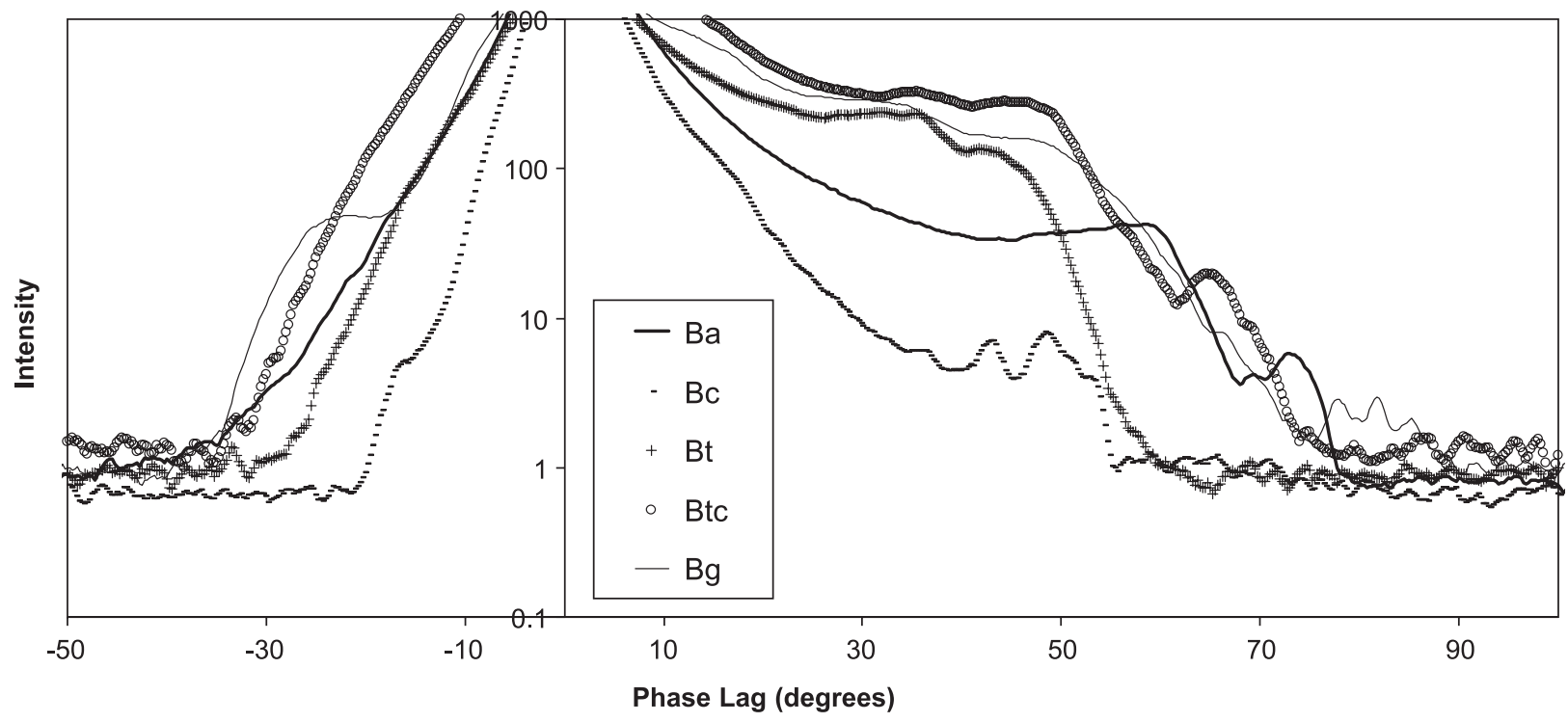

Fig. 5. Phase-lag spectra for spores normalized to $B a$ maximum (3912) near zero phase lag. $B a, B c$, and $B t$ spores show distinctly different patterns at large phase lags. 
differences. An additional feature appears at 65 degrees in the $B t c$ distribution, which we attribute to some material property of the parasporal crystals. Below 50 degrees phase lag, $B a$ spore distribution does not exhibit the features that are present in $B t$ and $B g$. Ba shows a small feature at about 60 degrees that is present in none of the other distributions. The phase spectrum for $B g$ is qualitatively different from all the others. It shows a significant feature in the low phase wing at about -20 degrees, not observed in the more closely related spores. The nature of the differences in spore materials that produce the observe heterogeneity are unknown to us, but the surfaces of $B a, B t, B c$, and $B g$ spores have regions with significantly different material properties.

We were unable to reliably classify spores using individual AFM images; however, we were able to distinguish populations of spores of these closely related organisms by analyzing AFM images of fewer than 20 samples of spore surfaces of each organism. Phase image data was the most informative about spore differences. Taken together, the data from the comparisons of AFM images show that it is possible to distinguish small groups of organisms by AFM analysis of spore surface features.

\section{Discussion}

The larger, vein or net-like vertical features observed on spore surfaces were thought to represent inclusions underlying the surface rather than bona fide surface features. Commonly observed in studies of spore sections, the ellipsoidal shape of the spore can be distended by these features (Beaman et al., 1972). The subtleness of the features observed on the surface of these spores contrasts the complex, deep sculpturing observed in early studies of Bacillus spores using relatively low resolution TEM images of carbon replicas (Bradley and Franklin, 1958; Bradley and Williams, 1957). TEM freezeetch preparations of B. sphaericus and B. megaterium (Holt and Leadbetter, 1969) or B. cereus (Aronson and Fitz-James, 1976) spore surfaces showed granular structures much like the granularity seen in images in this study. $B t$ spores react rapidly to changes in water availability (Chada et al., 2003; Westphal et al., 2003) and these features may simply result from relative dehydration of the spores. Although there was not precise humidity control of spore samples, the dry $\mathrm{N}_{2}$ purge gas surrounding the spores during AFM measurements ensured a consistent measurement environment with low relative humidity.

Phase images, resulting from surface-probe interactions and surface viscoelasticity, provided much more surface information than did the relatively simple height images. Phase lags are influenced by variations in interface material properties such as adhesion, friction, and viscoelasticity (Babcock and Prater, 1995). Primarily, phase images map stiffness variations on a surface. A stiffer region has a more positive shift and appears brighter (Magonov et al., 1997).

Although absolute surface morphology differences between $B a, B c$, and $B t$ spores were not apparent, the spores' diverse surface properties, such as hydrophobicity and adhesion, suggest that there are significant inter-specific differences in spore surfaces. This work represents a step in linking the behavior of the spores to specific biochemical structures inherent to spore surfaces.

The natural surface morphology of Bacillus spores has been revealed by AFM. The experimental protocol presented here is a simple, effective means for studying the detailed surface morphology of bacterial spores without the chemical or physical pretreatment necessary for scanning or transmission electron microscopy.

We measured variation within single strains of four species. Each species has many known isolates or strains. Certainly, additional investigation of variability within and between strains of single species could be appropriate.

\section{Acknowledgements}

We thank Dr Eric Holwitt and Dr Johnathan Kiel of the Air Force Research Laboratories Biomechanisms and Modeling Branch for providing the microorganisms and growth technology for this work, and Lieutenant Colonel Peter LaPuma for administrative assistance. This research was sponsored, in part, through the JSAWM Program, by the US Army, ERDEC/SCBRD and AFIT/ENR Emerging Thrust Initiative. The views expressed in this article are those of the authors and do not reflect the official policy or position of the United States Air Force, Department of Defense, or the US Government.

\section{References}

Aronson, A.I., Fitz-James, P., 1976. Structure and morphogenesis of the bacterial spore coat. Bacteriological Reviews 40, 360-402.

Babcock, K.L., Prater, C.B. 1995. Phase Imaging: Beyond Topography. Digital Instruments Application Notes.

Bar, G., Brandsch, R., Bruch, M., Delineaue, L., Whangbo, M.-H., 2000. Examination of the relationship between phase shift and energy dissipation in tapping mode atomic force microscopy by frequency-sweep and forceprobe measurements. Surface Science 444, L11-L16.

Beaman, T.C., Pankratz, H.S., Gerhardt, P., 1972. Ultrastructure of the exosporium and underlying inclusions in spores of Bacillus megaterium strains. Journal of Bacteriology 109, 1198-1209.

Binnig, G., Quate, C.F., Gerber, C., 1986. Atomic force microscope. Physical Review Letters 56, 930-933.

Bradley, D.E., Williams, D.J., 1957. An electron microscope study of the spores of some species of the genus Bacillus using carbon replicas. Journal of General Microbiology 17, 75-79.

Bradley, D.E., Franklin, J.G., 1958. Electron microscope survey of the surface configuration of spores of the genus Bacillus. Journal of Bacteriology 76, 618-630.

Chada, V.G.R., Sanstad, E.A., Wang, R., Driks, A., 2003. Morphogenesis of Bacillus spore surfaces. Journal of Bacteriology 185, 6255-6261.

Charlton, S., Moir, A.J.G., Baillie, L., Moir, A., 1999. Characterization of the exosporium of Bacillus cereus. Journal of Applied Microbiology 87, 241-245.

Daffonchio, D., Cherif, A., Borin, S., 2000. Homoduplex and Heteroduplex polymorphisms of the amplified ribosomal $16 \mathrm{~S}-23 \mathrm{~S}$ internal transcribed spacers describe genetic relationships in the 'Bacillus cereus group'. Applied and Environmental Microbiology 66, 5460-5468.

Doyle, R.J., Nedjat-Haiem, F., Singh, J.S., 1984. Hydrophobic characteristics of Bacillus spores. Current Microbiology 10, 329-332. 
Dufrene, Y.F., 2000. Direct characterization of the physicochemical properties of fungal spores using functionalized AFM probes. Biophysical Journal 78, 3286-3291.

Dufrene, Y.F., 2002. Atomic force microscopy, a powerful tool in microbiology. Journal of Bacteriology 184, 5205-5213.

Dufrene, Y.F., Boonaert, C.J., Gerin, P.A., Asther, M., Rouxhet, P.G., 1999. Direct probing of the surface ultrastructure and molecular interactions of dormant and germinating spores of Phanerochaete chrysosporium. Journal of Bacteriology 181, 5350-5354.

Gerhardt, P., Ribi, E., 1964. Ultrastructure of the exosporium enveloping spores of Bacillus cereus. Journal of Bacteriology 88, 1774-1789.

Hansma, H.G., 1999. Varieties of imaging with scanning probe microscopes. Proceedings of the National Academy of Sciences 96, 14678-14680.

Helgason, E., Okstad, O.A., Caugant, D.A., Johansen, H.A., Fouet, A., Mock, M., Hegna, I., Kolsto, A.-B., 2000. Bacillus anthracis, Bacillus cereus, and Bacillus thuringiensis - one species on the basis of genetic evidence. Applied and Environmental Microbiology 66, 2627-2630.

Higgins, J.A., Cooper, M., Schroeder-Tucker, L., Black, S., Miller, D., Karns, J.S., Manthey, E., Breeze, R., Perdue, M.L., 2003. A field investigation of Bacillus anthracis contamination of US department of agriculture and other Washington, DC, buildings during the Anthrax attack of October 2001. Applied and Environmental Microbiology 69, 593-599.

Holt, S.C., Leadbetter, E.R., 1969. Comparative ultrastructure of selected aerobic spore-forming bacteria: a freeze-etching study. Bacteriological Reviews 33, 346-378.

Jandt, K.D., 2001. Atomic force microscopy of biomaterials surfaces and interfaces. Surface Science 491, 303-332.

Koshikawa, T., Yamazaki, M., Yoshimi, M., Ogawa, S., Yamada, A., Watabe, K., Torii, M., 1989. Surface hydrophobicity of spores of Bacillus spp. Journal of General Microbiology 135, 2717-2722.

Liu, H., Bergman, N.H., Thomason, B., Shallom, S., Hazen, A., Crossno, J., Rasko, D.A., Ravel, J., Read, T.D., Peterson, S.N., Yates, J., Hanna, P.C., 2004. Formation and composition of the Bacillus anthracis endospore. Journal of Bacteriology 186, 164-178.

Magonov, S.N., Elings, V., Whangbo, M.-H., 1997. Phase imaging and stiffness in tapping-mode atomic force microscopy. Surface Science 375, L385-L391.

Muller, D.J., Baumeister, W., Engel, A., 1996. Conformational change of the hexagonally packed intermediate layer of Deinococcus raiodurans monitored by atomic force microscopy. Journal of Bacteriology 178, 3025-3030.

Radmacher, M., Tillmann, R.W., Fritz, M., Gaub, H.E., 1992. From molecules to cells: imaging soft samples with the atomic force microscope. Science 257, 1900-1905.
Ronner, U., Husmark, U., Henriksson, A., 1990. Adhesion of Bacillus cereus in relation to hydrophobicity. Journal of Applied Bacteriology 69, $550-556$.

Rosovitz, M.J., Voskuil, M.I., Chambliss, G.H., 1998. Bacillus. In: Collier, L., Balows, A., Sussman, M. (Eds.), Topey \& Wilson's Microbiology and Microbial Infections. Oxford University Press, New York, pp. 709-729.

Schnepf, E., Crickmore, N., Van Rie, J., Lereclus, D., Baum, J., Feitelson, J., Zeigler, D.R., Dean, D.H., 1998. Bacillus thuringiensis and its pesticidal crystal proteins. Microbiology and Molecular Biology Reviews 62, 775806.

Sokolov, I.Y., Firtel, M., Henderson, G.S., 1996. In situ high-resolution atomic force microscope imaging of biological surfaces. Journal of Vacuum Science and Technology A 14, 674-678.

Thorne, C.B., 1993. Bacillus anthracis. In: Sonenshein, A.L. (Ed.), Bacillus Subtilis and Other Gram-Positive Bacteria: Biochemistry, Physiology, and Molecular Genetics. American Society for Microbiology, Washington, DC, pp. 113-124.

Ticknor, L.O.A.-B., Kolsto, K.K., Hill, P., Keim, M.T., Tonks, Laker M., Jackson, P.J., 2001. Fluorescent amplified fragment length polymorphism analysis of Norwegian bacillus cereus and bacillus thuringiensis soil isolates. Applied and Environmental Microbiology 67, 4863-4873.

Todd, S.J., Moir, A.J.G., Johnson, M.J., Moir, A., 2003. Genes of Bacillus cereus and Bacillus anthracis encoding proteins of the exosporium. Journal of Bacteriology 185, 3373-3378.

Umeda, A., Saito, M., Amako, K., 1998. Surface characteristics of gramnegative and gram-positive bacteria in an atomic force microscope image. Microbiology and Immunology 42, 159-164.

van der Mei, H.C., Busscher, H.J., Bos, R., de Vries, J., Dufrene, Y.F., 2000. Direct probing by atomic force microscopy of the cell surface softness of a fibrillated and nonfibrillated oral streptococcal strain. Biophysical Journal $78,2668-2674$

Vilas-Boas, G., Sanchis, V., Lereclus, D., Lemos, M.V.F., Bourguet, D., 2002. Genetic differentiation between sympatric populations of Bacillus cereus and Bacillus thuringiensis. Applied and Environmental Microbiology 68, 1414-1424.

Westphal, A.J., Price, P.B., Leighton, T.J., Wheeler, K.E., 2003. Kinetics of size changes of individual Bacillus thuringiensis spores in response to changes in relative humidity. Proceedings of the National Academy of Sciences 100, 3461-3466.

Zolock, R.A., 2002. Characterization of the Surface Morphology of Bacillus Spores by Atomic Force Microscopy. Air Force Institute of Technology MS Thesis AFIT/GEE/ENV/02M-17. 